\title{
Higher dosage nicotine patches increase one-year smoking cessation rates: results from the European CEASE trial
}

\author{
P. Tønnesen*, P. Paoletti**, G. Gustavsson ${ }^{+}$, M.A. Russell ${ }^{\#}$, R. Saracci ${ }^{\S}$, \\ A. Gulsvik", B. Rijcken", U. Sawe ${ }^{+}$, members of the Steering Committee of \\ CEASE on behalf of the European Respiratory Society
}

Higher dosage nicotine patches increase one-year smoking cessation rates: results from the European CEASE trial. P. Tønnesen, P. Paoletti, G. Gustavsson, M.A. Russell, R. Saracci, A. Gulsvik, B. Rijcken, U. Sawe members of the Steering Committee of CEASE on behalf of the European Respiratory Society. C)ERS Journals Ltd 1999.

ABSTRACT: The Collaborative European Anti-Smoking Evaluation (CEASE) was a European multicentre, randomized, double-blind placebo controlled smoking cessation study. The objectives were to determine whether higher dosage and longer duration of nicotine patch therapy would increase the success rate.

Thirty-six chest clinics enrolled a total of 3,575 smokers. Subjects were allocated to one of five treatment arms: placebo and either standard or higher dose nicotine patches (15 mg and $25 \mathrm{mg}$ daily) each given for 8 or 22 weeks with adjunctive moderately intensive support.

The 12 month sustained success rates were: $25 \mathrm{mg}$ patch for 22 weeks (L-25), $15.4 \% ; 25 \mathrm{mg}$ patch for 8 weeks $(\mathrm{S}-25), 15.9 \% ; 15 \mathrm{mg}$ patch for 22 weeks (L-15), $13.7 \%$; $15 \mathrm{mg}$ patch for 8 weeks (S-15), 11.7\%; and placebo (P-0) 9.9\% (placebo versus $15 \mathrm{mg}, \mathrm{p}<0.05 ; 25 \mathrm{mg}$ versus $15 \mathrm{mg}, \mathrm{p}<0.03 ; 25 \mathrm{mg}$ versus placebo, $\mathrm{p}<0.001$, Chisquared test). There was no significant difference in success rate between the two active treatment durations. Of the first week abstainers $(n=1,698), 25.1 \%$ achieved success at 12 months as opposed to first week smokers, $2.7 \%$ of 1,877 subjects $(\mathbf{p}<\mathbf{0 . 0 0 1})$.

In summary, a higher than standard dose of nicotine patch was associated with an increase in the long-term success in smoking cessation but continuation of treatment beyond 8-12 weeks did not increase the success rates.

Eur Respir J 1999; 13: 238-246.
*Dept of Pulmonary Medicine, Gentofte Hospital, Hellerup, Denmark, **Eli Lilly, Indianapolis, Ohio, USA, ${ }^{+}$Pharmacia \& Upjohn, Helsingborg, Sweden, ${ }^{\#}$ Smoking Section, Institute of Psychiatry, University of London, London, UK, ${ }^{5}$ International Agency for Research on Cancer, World Health Organization, Lyon, France, "Dept of Pulmonary Medicine, Haukeland Hospital, Bergen, Norway, "Dept of Epidemiology, University of Groningen, Groningen, The Netherlands.

Correspondence: P. Tønnesen, Dept of Pulmonary Medicine, Gentofte Hospital, Niels Andersensvej, DK-2900 Hellerup, Denmark. Fax: 4539200593

Keywords: Dose, duration, nicotine patches, smoking cessation

Received: April 171998 Accepted after revision October 51998

This trial was conducted on behalf of the ERS by the Occupational and Epidemiology Assembly and with the sponsorship of Pharmacia \& Upjohn, Helsingborg, Sweden.
Nicotine is the drug of choice to assist smoking cessation. In a recent meta-analysis of 42 nicotine chewing gum studies and nine patch studies, comprising 17,000 subjects, the odds ratios of long-term success were 1.61 for gum and 2.07 for patch compared with placebo [1]. Effective use of nicotine gum, however, requires careful instructions. Transdermal uptake of nicotine from patches is approximately $1 \mathrm{mg}$ nicotine $\cdot \mathrm{h}^{-1}[2]$. Two large multicentre studies using 16 and $24 \mathrm{~h}$ nicotine patches in primary care both reported a doubling of success rate compared with placebo $[3,4]$. The only study to date that compared the 16 and $24 \mathrm{~h}$ patches found no significant difference in efficacy [5].

The standard doses delivered by the 16 and $24 \mathrm{~h}$ patches are $15 \mathrm{mg}$ and $21 \mathrm{mg}$ of nicotine, respectively [6,7]. A dose-response effect on six-month success rate was observed in a multicentre study that compared 21,14 , and 7 $\mathrm{mg}$ nicotine $24 \mathrm{~h}$ patches used for 6 weeks followed by a $6-$ week tapering period [8]. However, a dose-response effect

For editorial comments see page 231 has not been examined at delivery levels above $1 \mathrm{mg}$ nicotine $\cdot h^{-1}[9]$.

Regarding the duration of nicotine substitution, periods varying from 6-18 weeks including a dose-tapering period, have been used in most trials. No direct comparisons of different durations of treatment have been performed $[1,2$, 7], and there is little evidence to date that shorter periods of treatment are less effective than longer periods.

As tobacco smoking is the main causative factor for chronic obstructive pulmonary disease (COPD) and lung cancer, it should be mandatory for chest physicians to implement smoking cessation as an important part of the preventive work offered by chest departments. Thus, in this study chest physicians recruited "healthy" smokers in order to prevent the onset of COPD and lung cancer.

The main objectives of the Collaborative European Anti-Smoking Evaluation (CEASE) were to examine whether long-term success rates (i.e. complete abstinence sustained for $1 \mathrm{yr}$ ) could be increased by using higher than standard doses of transdermal nicotine, and/or by prolonging the patch treatment period. 


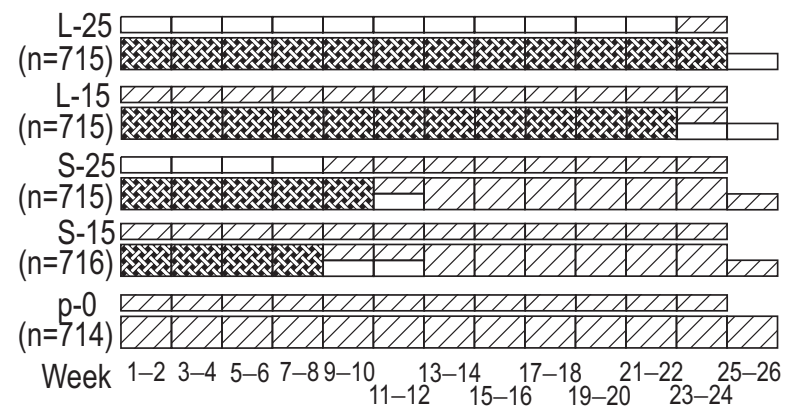

Fig. 1. - Treatment and trial design. $\square: 10 \mathrm{mg}$ nicotine patch; $: 15 \mathrm{mg}$ nicotine patch; $\mathbb{Z}$ : placebo patch.

\section{Subjects and methods}

\section{Study design}

This was a placebo-controlled, double-blind trial using transdermal nicotine patches in five parallel treatment arms as an adjunct to moderate advice and support in chest clinics. Smokers (>14 cigarettes daily) were randomly allocated to one of the following five treatment arms (fig. 1). 1) L-25: $25 \mathrm{mg}$ nicotine patch $(15 \mathrm{mg}$ patch plus 10 $\mathrm{mg}$ patch) for 22 weeks, followed by $15 \mathrm{mg}$ patch for 2 weeks and $10 \mathrm{mg}$ patch for 2 weeks (high dose and long duration). 2) S-25: $25 \mathrm{mg}$ nicotine patch (15 mg patch plus $10 \mathrm{mg}$ patch) for 8 weeks, followed by $15 \mathrm{mg}$ patch for 2 weeks and $10 \mathrm{mg}$ patch for 2 weeks (high dose and short duration). 3) L-15: $15 \mathrm{mg}$ nicotine patch plus placebo patch for 22 weeks, followed by $10 \mathrm{mg}$ patch for 4 weeks (standard dose and long duration). 4) S-15: 15 mg nicotine patch plus placebo patch for 8 weeks, followed by $10 \mathrm{mg}$ patch for 4 weeks (standard dose and short duration). 5) P-0: two placebo patches for a total of 26 weeks.

Active and placebo patches were identical in appearance and packaging. In order to maintain blinding, all subjects continued to use two patches for a total of 26 weeks i.e. active patches were replaced with placebo patches in the short duration groups. To gradually taper the nicotine patch dose by the same fraction for both the high and standard dose and also because of the two patch sizes available in the study, the tapering doses were $25-15-10 \mathrm{mg}$ and $15-$ 10-10 mg. A computer-generated allocation list was prepared centrally and allocated subjects to treatment numbers. Randomization, which was stratified only by centre, took place at enrolment day in each centre. The five treatment groups were balanced in equal numbers within centres.

\section{Centres}

Thirty-six clinical centres in 17 countries participated in the study (see Appendix). Principal investigators at each centre were chest physicians (31), but nurses (2) and in some cases lung function technicians (1) or psychologists (1) were also involved in patient contact. There was one missing return. In 24 centres, both physicians and nurses had patient contact. All investigators participated in a oneday training symposium before the start of the study, and a one-day training session was also conducted at each clinical centre for the staff. A videotape showing all practical procedures and a simulated patient consultation was shown before commencing. Detailed guidelines about verbal information and support at each visit were provided in the protocol. Eighteen study centres had prior experience of smoking cessation programmes before CEASE and 17 centres had no previous experience $(1$ missing return). Each centre was expected to enrol 100 smokers. The study was approved by the regional and local ethics committees and the national Health Boards.

\section{Subjects}

Smokers were recruited from the general population following standard guidelines in the study protocol. Twenty-eight centres advertised in local newspapers, one used local radio advertisements, five arranged press conferences resulting in news articles, three used wall posters in public areas of the hospital or its vicinity and two used existing databases from previous recruitment to smoking cessation programmes (three centres used a mixture of these methods).

\section{Inclusion and exclusion criteria}

Smokers aged 20-70 yrs who had smoked $>14$ cigarettes. day ${ }^{-1}$ for at least 3 yrs were recruited on a voluntary basis. Participants had to be motivated to stop smoking and had to have made at least one prior quit attempt. Exclusion criteria were: myocardial infarction in the preceding 3 months; unstable angina; severe cardiac arrhythmia; pregnant or lactating females; under psychiatric care or medication; alcohol or any other drug abuse; eczema; severe or malignant disease; and existing use of nicotine substitution products and/or participation in formal smoking cessation programmes in the last 6 months.

\section{Treatment}

The nicotine patches used contained $0.83 \mathrm{mg} \cdot \mathrm{cm}^{-2} \mathrm{ni}-$ cotine and delivered $15 \mathrm{mg}\left(30 \mathrm{~cm}^{2}\right)$ and $10 \mathrm{mg}\left(20 \mathrm{~cm}^{2}\right)$ of nicotine during $16 \mathrm{~h}$, respectively (Nicorette $\mathbb{R}$ Patch, Pharmacia \& Upjohn, Helsingborg, Sweden) [2]. The maximal plasma nicotine concentration of $13 \mathrm{ng} \cdot \mathrm{mL}^{-1}$ is attained after $8 \mathrm{~h}$ with the $15 \mathrm{mg}$ patch. Smokers wore the patches during the daytime only, i.e. for approximately 16 h.

Patients received a brochure containing advice on smoking cessation and nicotine patch therapy, and were shown how to place the patches on the skin. The patches were applied in the morning on the arm or in the hip region and removed at bedtime. Unused patches were collected at each visit. Patients were told to stop smoking completely on quit day.

\section{Assessments}

At the enrolment visit the following assessments were performed. 1) Smoking history and current cigarette consumption. 2) Withdrawal symptoms (craving for cigarettes, irritability, anxiety, depression, drowsiness, difficulty in 
concentrating, restlessness, headache, hunger, sleep disturbances $)(0=$ not at all; $1=$ mild; $2=$ moderate; $3=$ severe $)$ [10]. An adverse mood score $(0-15)$ was calculated for each subject at each visit (including week 0 ), as the sum of the responses for irritability, anxiety, poor concentration, restlessness and depression from the withdrawal symptom inventory [3]. The change in score from week 0 was taken as a measure of withdrawal. As the withdrawal score was only analysed for the first 8 weeks, the treatment was the same in both active dose groups, and the data were pooled into three groups. In accordance with others, adverse mood scores were analysed in those individuals who were either completely abstinent or in "slippers" i.e. subjects who managed to control their smoking sufficiently to record an exhaled carbon monoxide level $<10$ parts per million (ppm) (i.e. comparable with a nonsmoker) at each visit [3, 11]. 3) Height, body weight, heart rate and blood pressure. 4) Plasma nicotine and cotinine were analysed using gas chromatography [12]. 5) CO levels were measured (Bedfont Monitor, Sittingbourne, UK) in expired air after a 15-s breath-hold with a $\mathrm{CO}$ value $<10 \mathrm{ppm}$ verifying abstinence [13]. Calibrations were carried out every 6 months. 6) Fagerstrom test of nicotine dependence (FTND) scoring 0 10 (most dependent) [14].

Following enrolment, smokers attended scheduled visits at week 0 (quit-day), and weeks 1, 2, 4, 8, 12, 22, 26 and 52 ; the allowed deviation for visits was \pm 3 days at weeks $1-8$, and \pm 2 weeks from week $12-52$. At each visit the smoking status (including expired $\mathrm{CO}$ ), body weight and withdrawal symptoms were assessed. Blood samples were collected from the nonpatch bearing arm for plasma nicotine and plasma cotinine determinations at week 4,8 , and 22, and after 12 months.

The plasma nicotine or plasma cotinine value measured during patch use, divided by the respective value when smoking at study entry, represented the level of nicotine or cotinine substitution.

\section{Efficacy evaluation}

Success (i.e. sustained abstinence) was defined as those subjects who continuously (at all visits) self-reported complete abstinence (answered no to: "Do you smoke?" and "Have you smoked since the last visit?") from week 2 up to 12 months and presented with an expired $\mathrm{CO}$ level $<10$ ppm at week 2 and all subsequent visits [3-5].

Subjects were classified as failures in cases of a missing $\mathrm{CO}$ verification, a missing visit, or use of other nicotinecontaining products. Subjects who did not attend a scheduled visit in spite of two requests to do so were also considered failures. Subjects who were smoking at week 2 or later were regarded as failures, but could continue treatment if they wished and smoked $<10$ cigarettes. day $^{-1}$.

Subjects who did not attend a scheduled visit were contacted by phone and requested to attend the clinic. If not willing to attend, the subjects' smoking status was recorded, as well as the reason for withdrawal from the study. Subjects lost to follow-up were regarded as failures. All the above failures were asked to attend the 12 month visit to complete the study.

Point prevalence at 12 months was defined as those subjects who attended this visit and claimed "not to smoke", verified with an exhaled CO level $<10 \mathrm{ppm}$, irrespective of earlier status.

Relapse was defined as subjects who had started to smoke at least one cigarette daily.

\section{Data management and statistical analysis}

At each centre, data were entered directly into a personal computer that was connected to a network (Quest, TechniLogix Inc., Alphenaan den Rijn, The Netherlands). This allowed a continuous daily update of the database at the two monitoring centres (the European Respiratory Society (ERS) Centre at the Institute of Clinical Physiology, Pisa, Italy and the Pharmacia \& Upjohn Centre, Helsingborg, Sweden) to be made. Case report forms were built into the computer program, which included immediate consistency checks of the entered data.

The two databases were compared and a small number $(<1 \%$ of all items) of inconsistencies corrected before proceeding to the statistical analysis performed at the ERS Pisa Centre. A sample size of at least 600 for each of the five treatment groups was estimated to allow a $90 \%$ probability of detecting statistical significance at the 5\% level (two-tailed test) for a difference of 10 versus $15 \%$ in the success rate up to one year [15]. Pearson's Chi-squared test, comparing the success rate at single points, was used in the primary outcome analysis. The log-rank test was also used to compare time to relapse between treatment groups. The heterogeneity of relative success rates (e.g. of active treatment versus placebo in different centres) was compared using the test described by BRESLOW and DAY [16]. Success was also presented as relative risk of abstinence with $95 \%$ confidence intervals (CI). The predictive importance of the different parameters was analysed using logistic regression analysis, in which the predictors were converted to binary variables using the median as the cutoff point. The main outcome measure was the 12 month success rate. All analysis have taken a p-value of $<0.05$ to represent statistical significance.

\section{Results}

\section{Subject characteristics}

Thirty-three centres enrolled 100 smokers, and three centres enrolled 99, 96 and 80 smokers, respectively, comprising a total of 3,575 subjects. The first patient was randomized to treatment in January 1994, and the last in October 1994; this patient had the 12 month follow-up in November 1995. The mean inclusion time per centre was 8 weeks (range, 2 days to 6.5 months).

Clean file and code breaking was conducted in December 1995. In 16 centres the patients spent $10-15 \mathrm{~min}$ in the clinic, in 13 centres $15-20 \mathrm{~min}$, in five centres $20-30$ $\mathrm{min}$ and in one centre $>30 \mathrm{~min}$ ( 1 missing return). Most of the time was devoted to collection of data, but at least 5 min was used to give advice about smoking cessation.

Twelve subjects used incorrect medications and were considered failures. Baseline characteristics of the five groups were similar (table 1). The sample comprised relatively young (mean age 41 yrs), heavy smokers (mean 
Table 1. - Baseline characteristics of the smokers in the five treatment groups

\begin{tabular}{lccccc}
\hline & L-25 & S-25 & L-15 & S-15 & P-0 \\
\hline Duration & Long & Short & Long & Short & \\
Dose & $25 \mathrm{mg}$ & $25 \mathrm{mg}$ & $15 \mathrm{mg}$ & $15 \mathrm{mg}$ & placebo \\
Numbers & 715 & 715 & 715 & 716 & 714 \\
Males \% & 52 & 53 & 52 & 51 & 52 \\
Age yrs & $40 \pm 10$ & $41 \pm 10$ & $40 \pm 10$ & $41 \pm 10$ & $41 \pm 10$ \\
Weight kg & $72 \pm 15$ & $71 \pm 14$ & $71 \pm 14$ & $73 \pm 14$ & $71 \pm 14$ \\
Age when started smoking yrs & $17 \pm 4$ & $17 \pm 4$ & $17 \pm 4$ & $17 \pm 4$ & $17 \pm 4$ \\
Cigarettes·day ${ }^{-1}$ & $28 \pm 11$ & $26 \pm 9$ & $26 \pm 10$ & $27 \pm 10$ & $27 \pm 10$ \\
Expired CO ppm & $26 \pm 13$ & $25 \pm 12$ & $24 \pm 11$ & $25 \pm 12$ & $26 \pm 13$ \\
Deep inhalation \% & 50 & 48 & 49 & 48 & 50 \\
Number of quit attempts & $2.9 \pm 3.0$ & $2.9 \pm 3.3$ & $3.1 \pm 4.9$ & $3.1 \pm 3.2$ & $3.0 \pm 3.3$ \\
FTND score & $5.6 \pm 2.1$ & $5.6 \pm 2.1$ & $5.6 \pm 2.1$ & $5.4 \pm 2.1$ & $5.6 \pm 2.1$ \\
P-cotinine ng.mL $\mathrm{mL}^{-1}$ & $277 \pm 112$ & $270 \pm 115$ & $270 \pm 113$ & $265 \pm 112$ & $270 \pm 112$ \\
P-nicotine ng·mL & $15.8 \pm 9.3$ & $14.9 \pm 9.2$ & $14.9 \pm 8.8$ & $14.7 \pm 8.8$ & $15.2 \pm 9.0$ \\
\hline
\end{tabular}

Data presented as mean \pm SD. ppm: parts per million; FTND: Fagerstrom test of nicotine dependence (score 1-10); P: plasma.

daily consumption of 27 cigarettes) who had tried to quit smoking on average three times before. Of the subjects, $34 \%$ had previously used nicotine replacement products.

The rate of attendance decreased with time: $2,815(78 \%)$ smokers attended at 4 weeks, whereas 2,367 (66\%), 1,965 (55\%), 1,506 (42\%), 1,271 (36\%), and 1,792 (50\%) attended the study at weeks $8,12,22,26$ and 52 , respectively. An extra effort was made to get subjects to return at the twelve-month follow-up. When subjects relapsed to daily smoking, most of these did not attend the scheduled visit or wanted to be withdrawn. Of the participants, 867 (24\%) completed the study at 12 months and 2,708 (76\%) withdrew during the 12 months. Reasons for withdrawal were: never stopped smoking $(122 ; 3 \%)$, started smoking $(1,089$; $30 \%)$, elevated CO $(43 ; 1 \%)$, not willing to continue in study $(250 ; 7 \%)$, adverse events $(73 ; 2 \%)$, exclusion criteria $(20 ; 1 \%)$, and other or several reasons $(320 ; 9 \%)$. The remaining group consisted of 769 (22\%) subjects lost to follow-up i.e. either no contact despite at least two telephone calls, or who withdrew by telephone.

\section{Success: dose and duration of treatment}

Although there were large differences in the overall outcome and in active versus placebo groups across the 36 centres (ranging 3-30\%), there was no statistically significant heterogeneity between centres in terms of the success rates of active compared with placebo treatment $(\mathrm{p}=0.26)$. Hence, all subsequent analyses were conducted on the pooled data from all centres. The sustained success rates for all five treatment groups are shown in table 2 .
There was no evidence of a difference in success between the standard and longer duration of patch treatment in terms of sustained $1 \mathrm{yr}$ outcome (14.6 versus $13.9 \%$, $\mathrm{p}=0.6$ ). There was also no evidence of patch dose by duration interaction $(p=0.30)$. However, at all time-points the success rate was significantly higher for the $15 \mathrm{mg}$ patch versus placebo group and for the $25 \mathrm{mg}$ versus 15 mg patch groups (Chi-squared test) (fig. 2). The 1 yr sustained success rates were $15.4 \%$ (L-25 mg), 15.9\% (S-25), $13.7 \%$ (L-15), 11.7 (S-15), and 9.9\% (P-0), respectively. The $25 \mathrm{mg}$ patch was more successful than placebo in sustaining $1 \mathrm{yr}$ abstinence (relative success rate $1.6(95 \%$ CI: $1.23-2.03)$ ), the $15 \mathrm{mg}$ patch was more successful than placebo (relative success rate, 1.3 (95\% CI: $1.02-$ $1.68), \mathrm{p}<0.04)$ and the $25 \mathrm{mg}$ patch was more successful than the $15 \mathrm{mg}$ patch (relative rate, 1.2 (95\% CI: $1.02-$ $1.48), \mathrm{p}=0.02$ ). The success rate up to 12 months was also significantly higher for the $15 \mathrm{mg}$ patch group compared with placebo $(\mathrm{p}<0.0001)$ and for the $25 \mathrm{mg}$ patch group compared with $15 \mathrm{mg}$ patch $(\mathrm{p}<0.0002)$ using the logrank test. Point prevalence at 12 months was $20.8 \%$ for the $25 \mathrm{mg}$ patch, $16.3 \%$ for the $15 \mathrm{mg}$ patch and $13.5 \%$ for placebo $(\mathrm{p}<0.0001)$.

\section{Predictors of success}

Abstinence in the first week was shown to be a strong predictor of outcome. For abstinent subjects $(n=1,698)$ compared with nonabstinent subjects $(n=1,877)$ in the first

Table 2. - Sustained success rate for the five treatment arms expressed as percentage success (number of successful subjects in parenthesis)

\begin{tabular}{lccccc}
\hline & $\mathrm{L}-25(\mathrm{n}=715)$ & $\mathrm{S}-25(\mathrm{n}=715)$ & $\mathrm{L}-15(\mathrm{n}=715)$ & $\mathrm{S}-15(\mathrm{n}=716)$ & $\mathrm{P}-0(\mathrm{n}=714)$ \\
\hline Week 2 & $73.3(524)$ & $75.2(538)$ & $68.4(489)$ & $67.7(485)$ & $49.3(352)$ \\
Week 4 & $49.7(355)$ & $50.6(362)$ & $43.1(308)$ & $40.9(293)$ & $27.7(198)$ \\
Week 8 & $36.9(264)$ & $40.8(292)$ & $32.5(232)$ & $29.2(209)$ & $20.7(148)$ \\
Week 12 & $30.5(218)$ & $34.0(243)$ & $27.3(195)$ & $23.6(169)$ & $17.5(125)$ \\
Week 22 & $22.2(159)$ & $23.9(171)$ & $19.9(142)$ & $17.3(124)$ & $13.2(94)$ \\
Week 26 & $19.6(140)$ & $21.0(150)$ & $18.5(132)$ & $15.4(110)$ & $12.2(87)$ \\
Week 52 & $15.4(110)$ & $15.9(114)$ & $13.7(98)$ & $11.7(84)$ & $09.9(71)$ \\
\hline
\end{tabular}

L-25: 25-mg patches for 22 weeks; S-25: 25 -mg patches for 8 weeks; $\mathrm{L}^{-1}$ 5: 15 -mg patches for 22 weeks; S-15: 15-mg patches for 8 weeks; P-0: placebo patches 


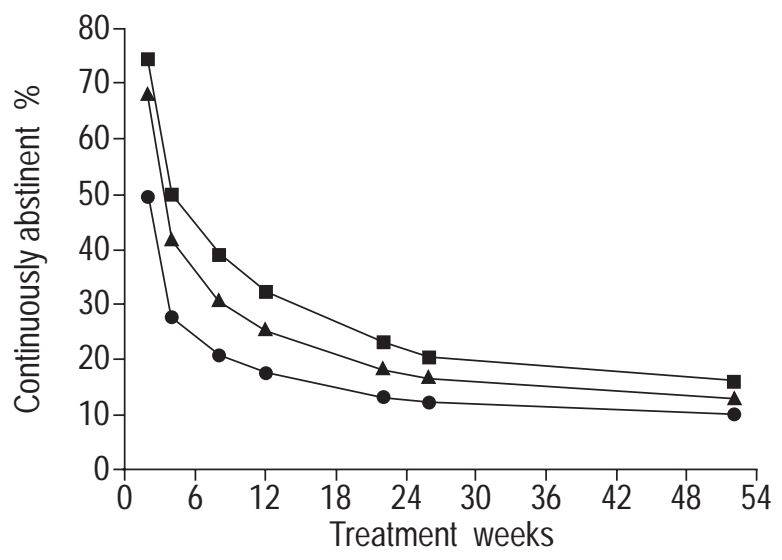

Fig. 2. - Sustained success rate for $25 \mathrm{mg}(\boldsymbol{\square})$ and $15 \mathrm{mg}(\boldsymbol{\Delta})$ nicotine patch groups and placebo $(\bullet)$ group for all 3,575 subjects.

week the 12 month success rate was 25.1 versus $2.7 \%$, respectively (Chi-squared test, $\mathrm{p}<0.001$ ).

The logistic regression analysis showed nicotine patch treatment, higher age, male sex, lower baseline cigarette consumption, more than one previous quit attempt and lower baseline CO level to be statistical significant pretreatment predictors of outcome (table 3 ).

\section{Withdrawal symptoms}

Adverse mood withdrawal symptoms peaked after one week and had declined to baseline levels by week 8 in all patch treatment groups (table 4, fig. 3). At weeks 1, 2 and 4 there was evidence of a dose-response relationship between adverse mood and patch dose $(\mathrm{p}<0.001, \mathrm{p}<0.001$, $\mathrm{p}<0.05$, respectively) with the placebo group experiencing the most severe, and the $25 \mathrm{mg}$ group the least severe, symptoms. By week 8 there was no evidence of any intergroup difference $(\mathrm{p}>0.2)$.

\section{Nicotine substitution and patch compliance}

Patch compliance for the four active nicotine patch arms in subjects who used the patch every day ranged 83$86 \%$ after 2 weeks and 57-64\% after 12 weeks (table 5).

Table 3. - Pretreatment predictors of 12 month abstinence

\begin{tabular}{|c|c|c|c|}
\hline Variable & $\begin{array}{l}\text { Odds } \\
\text { ratio }\end{array}$ & $95 \% \mathrm{CI}$ & p-value \\
\hline Sex (male versus female) & 1.50 & $1.20-1.86$ & $<0.01$ \\
\hline $\begin{array}{l}\text { Treatment } \\
\text { (nicotine versus placebo) }\end{array}$ & 1.49 & $1.11-1.99$ & $<0.01$ \\
\hline Quit attempts $(>1$ versus $<1)$ & 1.32 & $1.06-1.64$ & 0.01 \\
\hline Age (below versus over median) & 0.78 & $0.63-0.97$ & 0.02 \\
\hline $\begin{array}{l}\text { Number of cigarettes day }{ }^{-1} \\
\text { (below versus over median) }\end{array}$ & 1.30 & $1.03-1.65$ & 0.03 \\
\hline $\begin{array}{l}\text { Expired CO } \\
\text { (below versus over median) }\end{array}$ & 1.28 & $1.02-1.61$ & 0.03 \\
\hline $\begin{array}{l}\text { P-cotinine } \\
\text { (below versus over median) }\end{array}$ & 1.13 & $0.90-1.41$ & 0.29 \\
\hline FTND score (0-5 versus $6-10)$ & 1.06 & $0.85-1.34$ & 0.59 \\
\hline
\end{tabular}

CI: confidence interval; FTND: Fagerstrom test of nicotine dependence; P: plasma.
Table 4. - Adverse mood withdrawal symptoms during the first eight weeks of treatment for subjects with carbon monoxide $<10 \mathrm{ppm}$ in the $25 \mathrm{mg}, 15 \mathrm{mg}$ nicotine patch and placebo groups (possible score 0-15)

\begin{tabular}{|c|c|c|c|c|}
\hline Time-point & $25 \mathrm{mg}$ & $15 \mathrm{mg}$ & Placebo & p-value \\
\hline Week 1 & $0.26(1111)$ & $0.49(1060)$ & $1.23(423)$ & $<0.001$ \\
\hline Week 2 & $0.12(1032)$ & 0.35 (1046) & $0.79(393)$ & $<0.001$ \\
\hline Week 4 & 0.05 (1031) & 0.31 & $0.45(317)$ & $=0.02$ \\
\hline Week 8 & $-0.16 \quad(874)$ & -0.02 & $0.06(249)$ & $=0.22$ \\
\hline
\end{tabular}

Data are presented as the mean with the number of subjects in parentheses. Kruskal-Wallis tests (range of SD 2.9-3.4).

Compliance was lower in the placebo group at all time points.

In abstinent and patch-compliant subjects, the mean plasma-cotinine substitution after 4 weeks of nicotine patch treatment was higher for the $25 \mathrm{mg}$ group than for 15 $\mathrm{mg}$ patch group i.e. 58 and $41 \%(\mathrm{p}<0.0001$ for the difference of means) (table 6). Plasma nicotine substitution levels were also higher for the $25 \mathrm{mg}$ group compared with $15 \mathrm{mg}$ patch group after 4 weeks (87 versus $57 \%$, $\mathrm{p}<0.0001)$ and the overall nicotine substitution was higher than that for cotinine (table 7).

\section{Body weight change}

The increase in body weight in 1,784 subjects after $1 \mathrm{yr}$ was $4.9 \mathrm{~kg}(95 \% \mathrm{CI}: 4.5-5.2 \mathrm{~kg})$ for abstainers and $1.6 \mathrm{~kg}$ $(95 \% \mathrm{CI}, 1.4-1.9 \mathrm{~kg})$ for failures $(\mathrm{p}<0.0001)$.

Among successful subjects, the weight gain after $1 \mathrm{yr}$ was $5.1 \pm 3.7 \mathrm{~kg}$ for the $25 \mathrm{mg}$ group, $4.7 \pm 3.8 \mathrm{~kg}$ for the 15 $\mathrm{mg}$ group and $4.4 \pm 3.8 \mathrm{~kg}(\mathrm{SD})$ for the placebo group (NS). At entry, $52 \%$ of participants answered that they were afraid of gaining weight. Sixteen per cent of the subjects said that they would accept a gain of $>5 \mathrm{~kg}$ in body weight, whereas $25 \%$ were prepared to accept a gain of up to $2 \mathrm{~kg}$, $30 \%$ would accept a weight gain of $2-5 \mathrm{~kg}$, and $28 \%$ were not prepared to accept any weight gain.

\section{Adverse events}

Four myocardial infarctions (MI) occurred during the study period, which comprised 950 treatment years and

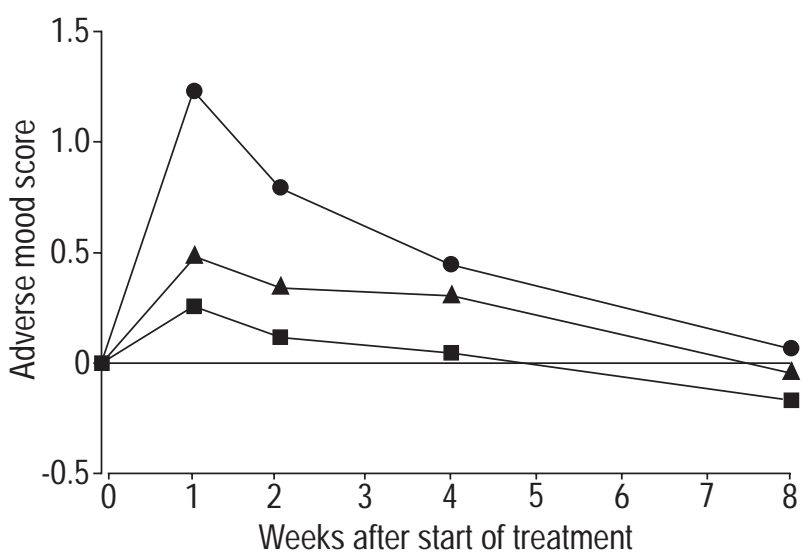

Fig. 3. - Adverse mood withdrawal symptoms during the first 8 weeks of treatment for abstinent subjects in the $25 \mathrm{mg}(\mathbf{\square})$ and $15 \mathrm{mg}(\boldsymbol{\Delta})$ nicotine patch groups and placebo (৩) group (possible score $0-15$ ). 
Table 5. - Subjects using patch every day

\begin{tabular}{lccccc}
\hline Time & $\begin{array}{c}\mathrm{L}-25 \\
(\mathrm{n}=715)\end{array}$ & $\begin{array}{c}\mathrm{S}-25 \\
(\mathrm{n}=715)\end{array}$ & $\begin{array}{c}\mathrm{L}-15 \\
(\mathrm{n}=715)\end{array}$ & $\begin{array}{c}\mathrm{S}-15 \\
(\mathrm{n}=716)\end{array}$ & $\begin{array}{c}\mathrm{P}-0 \\
(\mathrm{n}=714)\end{array}$ \\
\hline Week 2 & $86(641)$ & $86(649)$ & $84(637)$ & $83(635)$ & $78(574)$ \\
Week 4 & $76(598)$ & $78(609)$ & $75(572)$ & $69(566)$ & $71(466)$ \\
Week 8 & $59(514)$ & $63(552)$ & $61(486)$ & $54(470)$ & $51(339)$ \\
Week 12 & $62(437)$ & $63(470)$ & $64(398)$ & $57(377)$ & $53(280)$ \\
Week 22 & $41(340)$ & $30(354)$ & $38(312)$ & $29(274)$ & $35(213)$ \\
Week 26 & $52(291)$ & $47(290)$ & $53(274)$ & $45(222)$ & $51(186)$ \\
\hline
\end{tabular}

Data are presented as percentages with total number of subjects for whom data were available in parentheses. For definitions of treatments see legend to table 2 .

1,700 study years. One 59-yr-old male experienced MI during treatment with the $25 \mathrm{mg}$ nicotine patch, whereas one 48-yr-old male and one 50-yr-old male experienced MI after discontinuing treatment in the $15 \mathrm{mg}$ patch arm, and one 66-yr-old male had an MI in the placebo arm. This compared with the 10.2 cases (95\% CI: 4-16) expected during the study period based on calculations using data from the Framingham study [17, 18].

The overall incidence of adverse events was low, and these were generally transient. In order to examine possible dose-related adverse events the occurrence of events during the first 8 weeks of treatment in each of the three groups (25 mg, $15 \mathrm{mg}$ and placebo patch) were analysed. Nausea/vomiting were the only reported symptoms with a higher frequency in the $25 \mathrm{mg}$ group $(7.3 \%)$ compared with the $15 \mathrm{mg}$ group (5.4\%); these adverse events were more common in both active treatment groups than in the placebo group $(3.7 \%, \mathrm{p}<0.05)$. Headache was reported in $5.6 \%$ of subjects in the $25 \mathrm{mg}$ group, compared with $5.3 \%$ of the $15 \mathrm{mg}$ group and $3.9 \%$ of the placebo group. The incidence of insomnia was $4.9,5.4$, and $5.9 \%$, respectively. Palpitations and tachycardia were reported by $2.25 \%(25$ $\mathrm{mg}), 2.6 \%(15 \mathrm{mg})$ and $0.9 \%$ (placebo). Frequencies of nightmares during the first week of treatment were 8\% (25 $\mathrm{mg}), 7 \%(15 \mathrm{mg})$ and $6 \%$ (placebo), compared with $7 \%$, $8 \%$ and $7 \%$, respectively, for the week preceding start of treatment. The figures for vivid dreams were $20 \%$ (25 mg), $18 \%(15 \mathrm{mg})$ and $15 \%$ (placebo), respectively, compared with 18,19 and $17 \%$ before starting treatment. However, these two symptoms were collected using a checklist, which may explain the high frequency. Local adverse

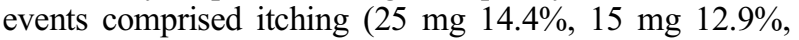

Table 6. - Plasma cotinine concentrations for the four nicotine patch arms for successful subjects (point-prevalence) who used the patch every day

\begin{tabular}{ccccc}
\hline & L-25 & S-25 & L-15 & S-15 \\
\hline Baseline & 277 & 270 & 270 & 266 \\
& $(100,682)$ & $(100,686)$ & $(100,683)$ & $(100,684)$ \\
Week 4 & 173 & 172 & 129 & 127 \\
& $(58,364)$ & $(57,374)$ & $(41,321)$ & $(43,284)$ \\
Week 8 & 169 & 170 & 124 & 130 \\
& $(53,237)$ & $(55,280)$ & $(37,217)$ & $(40,182)$ \\
Week 22 & 158 & - & 123 & - \\
& $(43,88)$ & & $(32,67)$ & \\
\hline
\end{tabular}

Data are presented as $\mathrm{ng} \cdot \mathrm{mL}^{-1}$, with, in parentheses, the per cent of baseline substitution followed by the number of subjects. For definitions of treatments see legend to table 2 .
Table 7. - Plasma nicotine concentrations for the four nicotine patch arms for successful subjects (point-prevalence) who used the patch every day

\begin{tabular}{lcccc}
\hline & L-25 & S-25 & L-15 & S-15 \\
\hline Baseline & 15.8 & 14.9 & 14.9 & 14.7 \\
& $(100,682)$ & $(100,686)$ & $(100,683)$ & $(100,684)$ \\
Week 4 & 14.1 & 13.7 & 9.2 & 9.3 \\
& $(84,364)$ & $(91,374)$ & $(59,321)$ & $(60,284)$ \\
Week 8 & 13.0 & 13.7 & 8.9 & 8.5 \\
& $(75,237)$ & $(83,280)$ & $(58,217)$ & $(56,182)$ \\
Week 22 & 12.4 & - & 6.9 & - \\
& $(79,88)$ & & $(44,67)$ & \\
\hline
\end{tabular}

Data are presented as $\mathrm{ng} \cdot \mathrm{mL}^{-1}$, with, in parentheses, the per cent of baseline substitution followed by the number of subjects. For definitions of treatments see legend to table 2 .

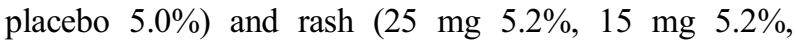
placebo $3.5 \%$ ) in the patch area. Two per cent of subjects discontinued treatment due to adverse events in both the active and placebo groups.

\section{Discussion}

This is the first study that directly compared different doses and treatment durations of nicotine replacement therapy. In terms of successful quit rates, no significant difference or even a trend was observed between the short and long treatment durations.

For the active treatment group the proportion of withdrawn subjects was approximately $30 \%$ after 2 weeks, $50 \%$ after 4 weeks, $66 \%$ after 8 weeks and $80 \%$ after 22 weeks, while for the placebo group, $50 \%$ were withdrawn after 2 weeks and $80 \%$ after 8 weeks. No effect was observed by prolonging active patch use from 8 to 22 weeks, the reason for failure (3\% withdrawn weekly) in that period was probably not caused by nicotine withdrawal symptoms but by other factors (external cues, loss of motivation to remain without cigarettes, weight gain).

A shorter treatment duration than $8+4$ weeks i.e. $4+4$ weeks is recommended by the United States Agency for Health Care Policy and Research [7]. A meta-analysis that included comparative studies found that use of nicotine patches for up to 8 weeks was as effective as longer duration of treatment [1]. Eight to 12 weeks of treatment probably represents the upper limit of duration. Data from the same meta-analysis, comprising 9,607 smokers, found no difference in effect in trials where the dose was tapered compared with abrupt withdrawal [1]. In one study involving 1,200 smokers, gradual reduction was no better at preventing relapse than abrupt withdrawal of patches after 12 weeks [3]. It should be remembered that the findings about duration of treatment for nicotine patches might not be applicable for other nicotine replacement products.

A dose-response effect was found in this study with an increase in the success rate at $1 \mathrm{yr}$ from $9.9 \%$ (placebo) to $12.8 \%$ with the $15 \mathrm{mg}$ patch and $15.7 \%$ with the $25 \mathrm{mg}$ patch. The dose-response curve shows a linear increase with no tendency to flatten, suggesting that a higher nicotine dose may have been even more effective. The success rate in the placebo group $(10 \%)$ was higher than 
that reported in most other studies which involved low-tomoderate intervention $[1,6,7]$.

In almost all smoking cessation studies it is usual that subjects who start smoking again during the early trial period are not willing to attend further scheduled visits despite great efforts from the investigators. This is not very surprising as relapse to cigarette smoking during the treatment period is a strong predictor of long-term failure. In the CEASE trial, $<22 \%$ of the participants were lost to follow-up, which is believed to be an acceptable level in this type of study.

The plasma nicotine and cotinine levels attained with the patches in the CEASE trial are in accordance with levels reported in earlier studies $[19,20]$. The $56 \%$ increase in plasma nicotine, from $9 \mathrm{ng} \cdot \mathrm{mL}^{-1}$ with the $15 \mathrm{mg}$ patch to $14 \mathrm{ng} \cdot \mathrm{mL}^{-1}$ with the $25 \mathrm{mg}$ patch, better reflects the $66 \%$ increase in patch dose than the cotinine levels (which only increased by $34 \%$ ). With respect to treatment efficacy, the plasma nicotine level is more important than cotinine, as nicotine is the active drug. Although plasma nicotine is more dependent on the sampling time because of its short half-life of 4-6 h following transdermal delivery, this possible source of variability might have been reduced as a result of the relatively large study population and instructions issued to the centres to try to keep the same appointment times.

The evidence of a dose-related suppression of tobacco withdrawal symptoms is consistent with the hypothesis that alleviation of withdrawal is an important mechanism underlying the efficacy of nicotine therapy. No difference in withdrawal was observed between groups after eight weeks, supporting the authors' finding of an upper limit of treatment duration of $\sim 8$ weeks. After 8 weeks, the adverse mood withdrawal symptoms returned to baseline level. A low rating of tobacco withdrawal symptoms was observed in this study (the highest mean of total score was 1.23 , with a possible maximal score of 15) and this is a consistent trait in many smoking cessation studies [3, 21]. Another problem with analysing withdrawal symptoms is selection bias due to a differential drop-out of subjects. Those subjects who start to smoke again are probably the ones suffering the most intense tobacco withdrawal symptoms; if they are unwilling to return for follow-up, their data will be missing. Thus, as the study progresses, the remaining subjects may be the selected nonsmoking group, comprising those suffering less nicotine withdrawal. In this study, an attempt was made to reduce one contributor to selection bias by not excluding subjects who managed to reduce smoking and attain an exhaled CO level $<10 \mathrm{ppm}$.

Weight gain can also be regarded as a withdrawal symptom resulting from increased hunger and increased calorie intake. However, the low and flat plasma nicotine levels achieved with the patch are inadequate to prevent a decrease in metabolic rate following cessation of cigarette use.

The actual weight gain of around $5 \mathrm{~kg}$ for abstainers after $1 \mathrm{yr}$ reflects the findings of other studies [3, 20]. About half of the participants in this study were afraid of gaining weight; only $16 \%$ would accept a gain of $>5 \mathrm{~kg}$ in body weight and $28 \%$ would not accept a weight gain of $>2 \mathrm{~kg}$.

In another study with the nicotine patch and placebo, it was found that weight gain during the first 2 weeks was positively correlated with $1 \mathrm{yr}$ success, while weight gain during the first 3 months correlated negatively with $1 \mathrm{yr}$ success, pointing to weight gain as one of several reasons for late relapse [22].

Initial cessation was a very strong predictor of long-term success as $25 \%$ of the first week abstainers attained 12 month success compared with only $3 \%$ of the subjects who continued smoking during the first week of treatment. In a smoking cessation study comprising 289 subjects, the authors reported a spontaneous quit rate of $0.7 \%$ after 12 months for primary failures [22]. Although active nicotine patches were offered to the failures (in contrast with the present trial) only $57 \%$ could be persuaded to return for a 12 month follow-up visit.

A multicentre study comprising 1,686 smokers using nicotine patches also identified early abstinence from smoking as the strongest predictor of sustained abstinence [23]. Of the first week abstainers, $25 \%$ of 277 in the active group and $28 \%$ of 182 in placebo group achieved longterm success, as opposed to first week smokers, $4 \%$ of 565 in the active group and $2 \%$ of 662 in the placebo group. In a similar study comprising 1,200 subjects, all but one of the 96 subjects achieving long-term abstinence quit during the first week of cessation [3]. Observations in these studies and the present study emphasize that the first weeks after quit day are the most important with regard to long-term outcome, and this needs to be underlined for the smokers when they have decided to quit. A 1-week trial of the patch, proceeding to longer use if abstinence is achieved, may be an effective approach.

This large multicentre trial once again confirmed that the nicotine patch, in conjunction with moderate adjunctive support, increases the successful quit rate compared with placebo, as also demonstrated in various other studies and settings [1].

The success rate of $16 \%$ after 1 yr may seem rather low and give rise to pessimism among the physicians. However, higher success rates (e.g. 36\%) have been reported in combination with more intensive supportive therapy [1], and lower success rates with brief support in general practice settings [3, 4]. Nonetheless, given the multiplicity and severity of the pathological consequences of tobacco smoke, even a modest gain in the proportion of smokers who quit has important public health consequences. In addition, it is estimated that smoking cessation treatment with nicotine replacement products is $\sim 8$ times more costeffective per life-yr saved than 300 other medical treatments [24].

This study also confirmed that nicotine replacement therapy appears to have few side-effects. The number of cardiac events was within the expected range, and other side-effects were mild and would not contra-indicate use of higher dose nicotine patches.

Several ways to try to improve outcome merit further research, including: 1) further increases in the nicotine patch dose, and doses of $44 \mathrm{mg}$ have already been tested $[9,25,26]$; 2) combination of different nicotine replacement formulations, and combined use of the patch with nicotine chewing gum has been explored in three studies [27-29]; 3) substitution by drug monitoring, as indicated in a recent small study [30]; and 4) preliminary data from combined use of nicotine patch and bupropion should be further explored [31].

In conclusion, an increase in outcome associated with enhancing the dose from 15 and $25 \mathrm{mg}$ nicotine patches was found, but there was no additional benefit with 
treatment longer than $8-12$ weeks. In those smoking $\geq 15$ cigarettes. day ${ }^{-1}$, the $25 \mathrm{mg}$ nicotine daytime patch need not be used for longer than 8-12 weeks with moderate supportive therapy. Abstinence from smoking in the first week was a strong predictor of long-term success.

\begin{abstract}
Acknowledgements. The authors and the investigators thank the members of the Scientific and Safety Committee of CEASE for their constructive criticism and supervision during the planning and implementation of the study and during the analysis of data. Thanks to J. Stapleton, London, for constructive revisions of the manuscript and calculation of the withdrawal score.
\end{abstract}

\section{Appendix}

Investigators in CEASE Trial: Austria: K. Aigner, F. Wimberger (Elisabethinen Hospital, Linz); Belgium: J. Van Meerbeeck, M. Wouters (University Hospital and VRGT, Antwerp), A. Lecomte, P. Windey (Hospital Erasme, Brussels), P. Bartsch, M. Reynders (Institut Provincial Ernest Malvoz, Liège); Denmark: H.B. Larsen (Aalborg Sygehus, Aalborg), T. Ewald, K. Mikkelsen (Gentofte Hospital, Hellerup), M. Christensen (Sønderborg Hospital, Sønderborg); England: P. Ind, N. Pride (Hammersmith Hospital, London), G.J. Gibson, T. Small (Freeman Hospital, Newcastle upon Tyne); Finland: K. Mattson, J. Lojander (Helsinki University Central Hospital Helsinki), K. Liippo (Central Hospital, Turku); France: D. Paillotin, J-F. Muir (Rouen University Hospital, Boisguillaume Cedex), A. Hirsch, D. Trédaniel (CHU Saint-Louis, Paris Cedex 10), A. Bohadana, Y. Martinet (Brabois Hospital, Vandouvre-Les Nancy); Germany: B. Wiesner, W. Pielesch (Zentralklinik Bad Berka GmbH, Bad Berka), P.C. Bauer (Ruhrlandklinik, Essen), P.L. Bölcskei (Klinikum Nürnberg, Nürnberg 9); Greece: C. Roussos, Z. Daniel (Evangelismos General Hospital, Athens), N.M. Siafakas, D. Bouros (University General Hospital, GRHeraklion, Crete); Ireland: L. Clancy (St James' Hospital, Dublin), P. Kelly (Peomount Hospital Newcastle, Dublin); Italy: G. Bonsignore, D. Dámico (Instituto di Fisipatologia, Palermo), L. Casali (University of Pavia, Pavia), F. Maggiorelli, M. Desideri (Clinica Medica II, Pisa); Norway: A. Gulsvik, P. Bakke (Bergen University Hospital, Bergen), J. Vilsvik, M. Sue-Chu (University of Trondheim, Trondheim); Poland: D. Górecka, J. Zielinski (Institute of Tuberculoses and Lung Disease, Warszawa); Portugal: C. Canteiro (Pulido Valente Hospital, Lisbon), J. Alves (Sankt Joâo Hospital, Porto); Spain: M.J. Cardona, Z. Cardona (Comarcal de Igualada Hospital, Barcelona), E. Monsó, J. Morera (Germans Trial Pujol Hospital, Barcelona), M. Castro Garcia, D. López (E.A.P. Justicia, Madrid), C.A. Jimenez-Ruiz, A. Ramos (Princesa Hospital, Madrid); Sweden: H. Gilljam (Huddinge University Hospital, Huddinge), D. Huberman (University of Lund, Lund); Switzerland: C.T. Bolliger, A.P. Perruchoud (University of Basel, Basel); The Netherlands: P.I. van Spiegel, J.G.I. Molenaar (Slotervaart Hospital, Amsterdam), M. Schlösser (Astmacentrum Hornerheide, Hornerheide), E.F.M. Wouters (Maastricht University, Maastricht).

\section{Steering committee}

P. Tønnesen (Denmark), P. Paoletti (Italy), A. Gulsvik (Norway), G. Gustavsson (Sweden), A. Hirsch (France), B. Rijcken (The Netherlands), M.A.H. Russell (UK), R. Saracci (France), U. Sawe (Sweden).

\section{Scientific committee}

N. Benowitz (USA), K.O. Fagerström (Sweden), F. Kauffmann (France), P. Delormas (France), J. Roca (Spain).

\section{Safety committee}

$$
\text { D. Olivieri (Italy), P. Vermeire (Belgium). }
$$

\section{Coordinating team}

Italy, E. Fornai, R. Cristofani, ERS, Pisa; Sweden, T. Danielsson, A. Westin, A. Rodin, B.M. Palsson, Pharmacia \& Upjohn, Helsinborg.

\section{References}

1. Silagy C, Mant D, Fowler G, Lancaster T. The effect of nicotine replacement on smoking cessation. In: Lancaster T, Silagy C, Fullerton D, eds. Tobacco Addiction Module of the Cochrane Database of Systematic Reviews. Oxford, The Cochrane Collaboration, 1997; pp. 1-18.

2. Palmer KJ, Buckley MM, Faulds D. Transdermal nicotine: a review of its pharmacodynamic and pharmacokinetic properties, and therapeutic efficacy as an aid to smoking cessation. Drugs 1992; 44(3): 498-529.

3. Stapleton JA, Russell MAH, Feyerabend C, et al. Dose effects and predictors of outcome in a randomised trial of nicotine patches in general practice. Addiction 1995; 90: $31-42$.

4. Imperial Cancer Research Fund General Practice Research Group. Randomised trial of nicotine patches in general practice: results at one year. $\mathrm{Br}$ Med $J$ 1994; 308: 1476-1477.

5. Daughton DM, Heatley SA, Prendergast JJ, et al. Effect of transdermal nicotine delivery system as an adjunct to low-intervention smoking cessation therapy. Arch Intern Med 1990; 151: 749-752.

6. Fiore MC, Smith SS, Jorenby DE, Baker TB. The effectiveness of the nicotine patch for smoking cessation. JAMA 1994; 271(24): 1940-1947.

7. Fiore MC, Bailey WC, Cohen SJ, et al. Smoking Cessation. Clinical Practice Guideline No. 18, AHCPR 960692. U.S. Department of Health and Human Services, Public Health Service, Agency for Health Care Policy and Research, 1996.

8. Transdermal Nicotine Study Group. Transdermal nicotine for smoking cessation. JAMA 1991; 22: 3133-3138.

9. Sachs DPL, Benowitz NL, Bostrom AG, Hansen MD. Percent serum replacement and success of nicotine patch therapy. Am J Respir Crit Care Med 1995; 151: A688.

10. American Psychiatric Association Diagnostic and Statistical Manual of Mental Disorders. IV. Washington D.C., American Psychiatric Association, 1994.

11. Hughes JR, Gust SW, Skoog K, Keenan RM, Fenwick JW. Symptoms of tobacco withdrawal: a replication and extension. Arch Gen Psychiatry 1991; 48: 52-59. 
12. Falkman SE, Burrows IE, Lundgren RA, Page BFJ. A modified procedure for determination of nicotine in blood. Analyst 1975; 100: 99-104.

13. Jarvis MJ, Russell MA, Saloojee Y. Expired air carbon monoxide: a simple breath test of tobacco smoke intake. Br Med J 1980; 281: 484-485.

14. Fagerström KO, Heatherton TF, Kozlowski LT. Nicotine addiction and its assessment. Ear Nose Throat J 1991; 69: 763-768.

15. Freedman LS. Tables of the number of patients required in clinical trials using log-rank test. Stat Med 1982; 1: 121-129.

16. Breslow NE, Day NE. Statistical Methods in Cancer Research. Vol. 2. Lyon, International Agency for Research on Cancer, 1987; 2: 75-76.

17. The Framingham Study. An Epidemiological Investigation of Cardiovascular Disease. U.S. Department of Health, Education, and Welfare. Public Health Service, National Institute of Health. National Heart and Lung Institute, DHEW publication. No. (NIH)76-1083, April 1976.

18. A report of the Surgeon General. Health consequences of smoking: cardiovascular disease. A report of the Surgeon General. US Department of Health and Human Services. Rockville, MD Public Health Service, Office on Smoking and health, 1983; pp. 63-156.

19. Paoletti P, Fornai E, Maggiorelli F, et al. Importance of baseline cotinine plasma values in smoking cessation: results from a double-blind study with nicotine patch. Eur Respir J 1996; 9: 643-651.

20. Tønnesen P, Nørregaard J, Simonsen K, Sawe U. A double-blind trial of a 16-hour transdermal nicotine patch in smoking cessation. $N$ Engl J Med 1991; 325: 311-315.

21. Nørregaard J, Tønnesen P, Simonsen K, Petersen L, Sawe U. Smoking habits in relapsed subjects from a smoking cessation trial after one year. Br J Addiction 1992; 87: $1189-1194$.
22. Nørregaard J, Tønnesen P, Petersen L. Predictors and reasons for relapse in smoking cessation with nicotine and placebo patches. Prev Med 1993; 22: 261-271.

23. Yudkin PL, Jones L, Lancaster T, Fowler GH. Which smokers are helped to give up smoking using transdermal nicotine patches? Results from a randomized, doubleblind, placebo-controlled trial. Br J Gen Pract 1996; 46: 145-148.

24. Fiscella K, Franks P. Are nicotine patches cost effective? JAMA 1996; 275: 1247-1251.

25. Jorenby DE, Smith SS, Fiore MC, et al. Varying nicotine patch dose and type of smoking cessation counselling. JAMA 1995; 274: 1347-1352.

26. Dale LC, Hurt RD, Offord KP, Lawson GM, Crogham IT, Schroeder DR. High-dose nicotine patch therapy: percentage of replacement and smoking cessation. JAMA 1995; 274: 1353-1358.

27. Fagerström KO, Schneider NG, Lunell E. Effectiveness of nicotine patch and nicotine gum as individual versus combined treatment for tobacco withdrawal symptoms. Psychopharmacology 1993; 110: 251-257.

28. Puska P, Korhonen HJ, Vartiainen E, Urjanheimo EL, Gustavsson G, Westin A. Combined use of nicotine patch and gum compared with gum alone in smoking cessation: a clinical trial in North Karelia. Tobacco Control 1995; 4: 231-235.

29. Kornitzer M, Boutzen M, Dramaix M, Thijs J, Gustavsson G. Combined use of nicotine patch and gum in smoking cessation: a placebo-controlled clinical trial. Prev Med 1995; 24: 41-47.

30. Sachs DPL, Benowitz NL. Individualizing medical treatment for tobacco dependence. Eur Respir J 1996; 9: 629631.

31. Hurt RD, Sachs DP, Glover ED, et al. A comparison of sustained-release bupropion and placebo for smoking cessation. N Engl J Med 1997; 337: 1195-1202. 